\title{
Physico-mechanical and morphological studies of jute/glass reinforced epoxy composites and its hybrids
}

DOI : 10.36909/jer.ICCEMME.15859

\author{
${ }^{1}$ Partha Pratim Das \\ ${ }^{2,3}$ Rohit Sahu \\ ${ }^{3}$ Krovvidi Srinivas \\ ${ }^{2}$ Shashi Prakash Dwivedi \\ ${ }^{1}$ Department of Mechanical Engineering, Amity School of Engineering \& Technology, Amity \\ University Uttar Pradesh, Noida, PIN: 201313, India \\ ${ }^{2}$ Department of Mechanical Engineering, G.L Bajaj Institute of Technology and Management, \\ Uttar Pradesh, Greater Noida, Pin: 201306, India \\ ${ }^{3}$ Department of Mechanical Engineering, Delhi Technological University, Shahbad Daulatpur, \\ Rohini, New Delhi, Pin: 110042, India
}

*Email: vijaychaudhary111gmail.com; Corresponding Author.

\begin{abstract}
Present research work emphasis on the fabrication and evaluation of the physico-mechanical performance of jute/glass fibre reinforced epoxy composites and their hybrids. Composite samples were fabricated by closed mold hand lay-up technique. Fibre/matrix interfacial adhesion of fractured specimens after mechanical tests was investigated using SEM (scanning electron microscope). Among J/Epoxy, G/Epoxy, J/G/Epoxy, J/G/Epoxy composites show the maximum Shore-D hardness value of 99 as compared to jute/epoxy and glass/epoxy of Shore-D hardness value of 96 and Hardness value of 98 Shore-D, respectively. Experimental studies have shown that there are superior Physico-mechanical properties of hybrid composites (jute/glass/epoxy).
\end{abstract}

Keywords: glass fibre; jute fibre; Physicomechanical properties; interfacial adhesion; SEM

\section{INTRODUCTION}

Fibre-reinforced polymer composites mainly comprise reinforcement and a polymeric matrix. Natural (bio) fibres are mainly extracted from nature such as plants (leaf fibre, fruit fibre and seed fibre), animals (hair, skin \& feather) \& minerals (Asbestos) (Pratim Das \& Chaudhary, 2020) (Bajpai et al., 2019), (Chaudhary et al., 2018). Jute, hemp, and flax are the natural fibres extracted from the surrounding stem of the plants. Natural fibre reinforced polymer composites (NFRPC) have a wide range of uses, including automotive, aerospace, and biomedical(Faruk et al., 2012; Ku et al., 2011; Nabi Saheb \& Jog, 1999). Before using these composites in suitable applications, characterization of these composite is very essential(Das, Chaudhary, et al., 2020), (Chaudhary \& Ahmad, 2020). 
Therefore, various tests were performed to study various properties (Mechanical, thermal, tribological). The fibres are mixed with matrix using the hand layup method, which is one of the most prominent and easy methods to develop composite specimens (Das, Srinivasa Rao, et al., 2020) (Das et al., 2021). The interface of fibre and matrix, type of natural fibre used, and processing technique affects the performance of the composites (Chaudhary et al., 2019), (Manickam et al., 2015). Many researchers investigated the mechanical characteristics of natural and synthetic fibre based polymeric materials and established conclusions based on their studies. The fabricated cellulosic wood strands/ polylactic corrosive (PLA) composites using expulsion and infusion forming process (Awal et al., 2015). The authors concluded that incorporation of bio-amide with PLA matrix enhanced the fibre/matrix interfacial strength, which results in better mechanical properties of developed composites. PLA (polylactic acid)based bio-composites laminate reinforced with Manicaria Saccifera palm fibre filaments are used to develop biocomposites. Using a hot press forming process, the authors developed the composite lamina using Manicaria Saccifera which enhanced the degrading performance of composites. The authors concluded that there is a temperature limit for composite handling (Porras et al., 2016).

Present study represents the fabrication and evaluation the Physico-mechanical properties of jute/glass/epoxy composites and its hybrids. Furthermore, interfacial damages between the fibre and the matrix were visualized using SEM.

\section{EXPERIMENTAL METHODS}

\section{Matrix and Fibre}

Jute fibre mat, glass fibre mat, epoxy resin and hardener (2:1), and silica gel were used for this study. For the development of the composites, natural fibre mats were used. Figure 1 depicted a jute fibre mat and a glass fibre mat. Resin (epoxy) and hardener is used as the matrix that binds fibres together.

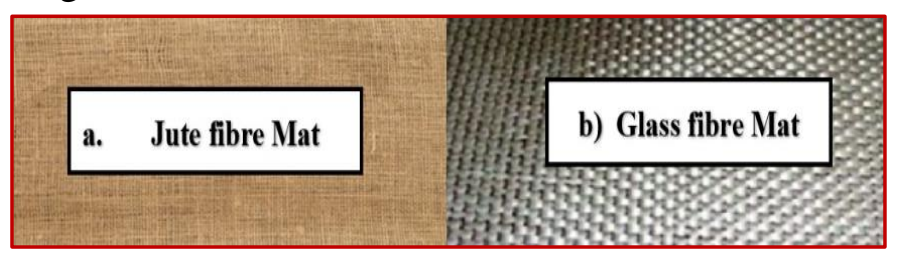

Figure 1 Fibre Mats of a) Jute, b) Glass. 


\section{Processing}

Jute fibre mat of 210 GSM and 360 GSM of glass fibre mat were used for the development of composite specimens using the hand layup method. The fibre weight percentage is $30 \%$ and the matrix percentage is $70 \%$. To avoid sticking of the epoxy from the inner surface of the mold, a releasing agent was spread over the direct contact surfaces. The epoxy glue was spread over the desired mold face using a brush and then the reinforcement was laid over it. The procedure was repeated until the desired thickness was achieved. After each layup, a wooden roller was used to extricate the entrapped gases or air bubbles. Following the completion of the operation, the mold was carefully opened after 24 hours and the composite laminates were removed. ASTM standards were used to cut the specimens. Figure 2 shows the developed J/Epoxy, G/Epoxy, and its hybrids (J/G/Epoxy) along with an abbreviation table.

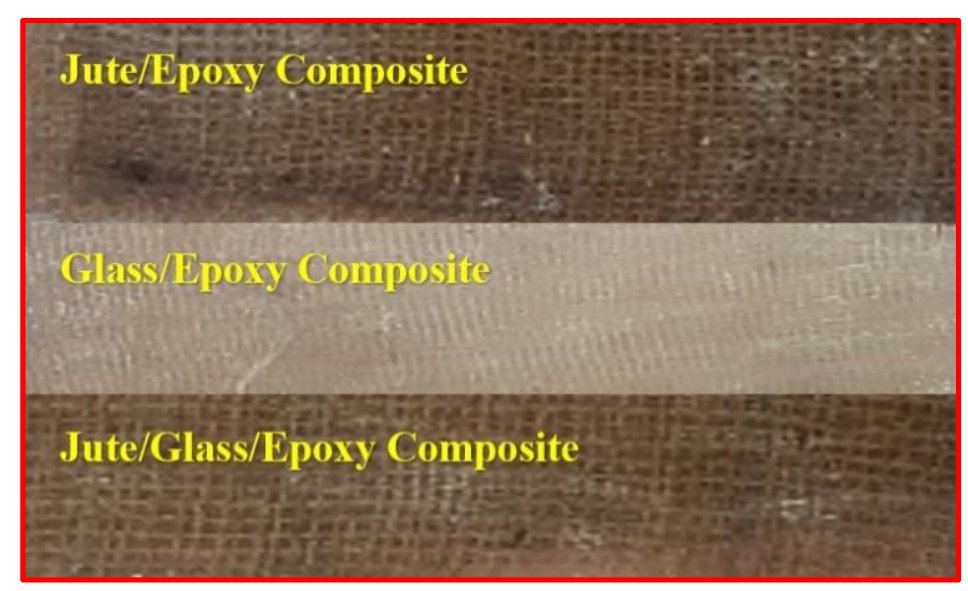

a) Jute, glass, and Hybrid Composites.

\begin{tabular}{|c|c|}
\hline Abbreviation & Description \\
\hline J/Epoxy & Jute/epoxy \\
\hline G/Epoxy & Glass/epoxy \\
\hline J/G/Epoxy & Jute/Glass/epoxy \\
\hline
\end{tabular}

b) Table of abbreviation.

Figure 2 a) Jute, glass, and Hybrid Composites, b) Table of abbreviation 


\section{CHARACTERIZATION: PHYSCIOMECHANICAL PROPERTIES}

\section{Hardness}

A shore Durometer: shore D is used to measure the hardness of the composite specimens. As an indenter, a $1.1 \mathrm{~mm}-1.4 \mathrm{~mm}$ diameter hardened steel rod having a conical point head of $30^{0}$ and a radius of $0.1 \mathrm{~mm}$ is used. The indenter applies a net force of $44.64 \mathrm{kN}$ to the developed composites.

\section{Tensile Testing}

ASTM D3039 Standard is used to develop the specimen and to study the tensile properties of the composite specimens. A Crosshead speed of $10 \mathrm{~mm} / \mathrm{min}$ was used for the tensile test using a Universal testing machine(UTM). Figure 3 depicts the load vs. extension curve during tensile testing.
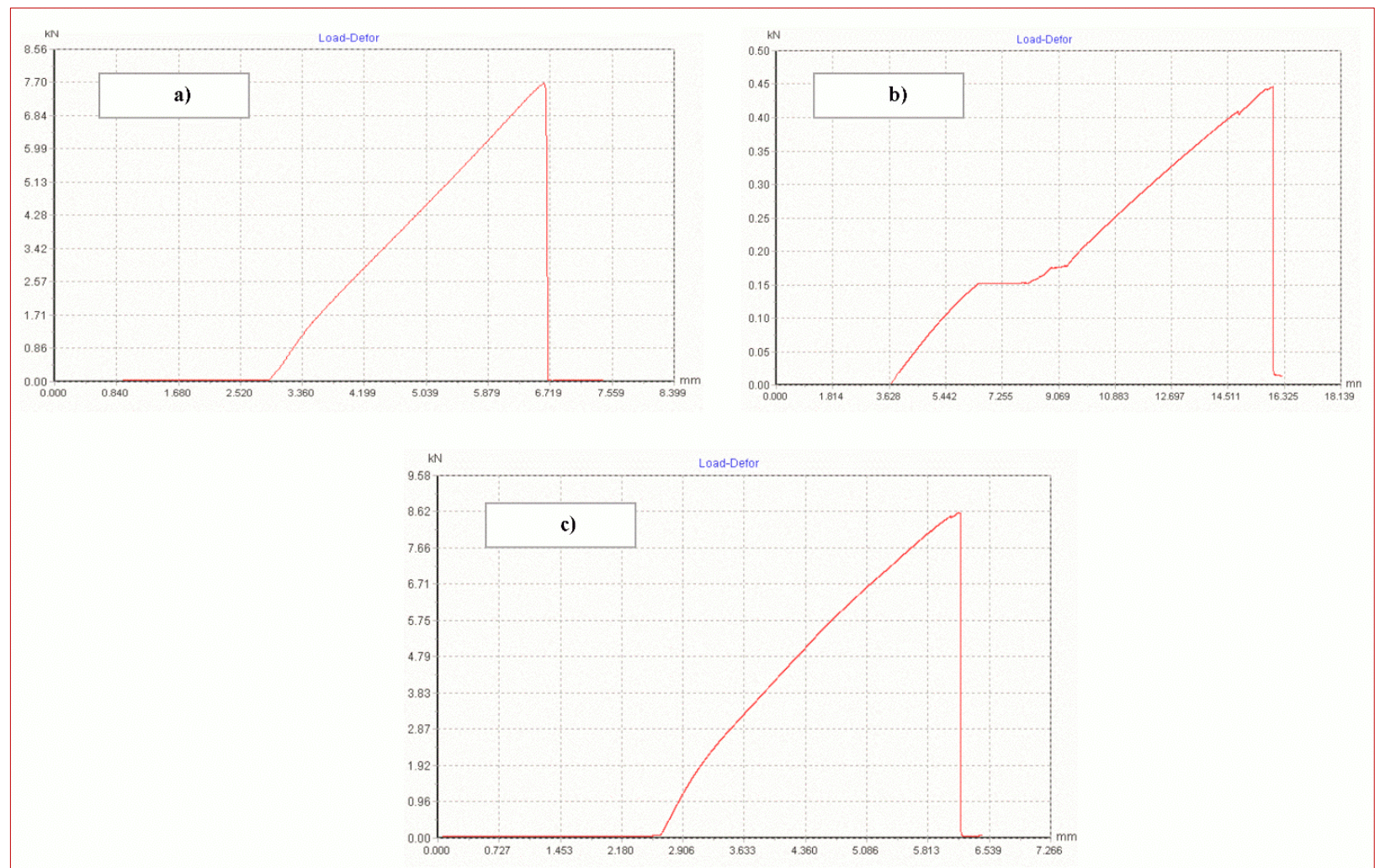

Figure 3 Load versus extension curve: a) GlEpoxy b) J/Epoxy and c) hybrid composites(J/G/Epoxy. 


\section{Flexural Testing}

Flexural test specimens were developed by ASTM D790 guidelines (Standards). Universal testing machine (UTM) with a crosshead speed of $2.5 \mathrm{~mm} / \mathrm{min}$ is used. During flexural testing, a load vs extension curve obtained is shown in Figure 4.

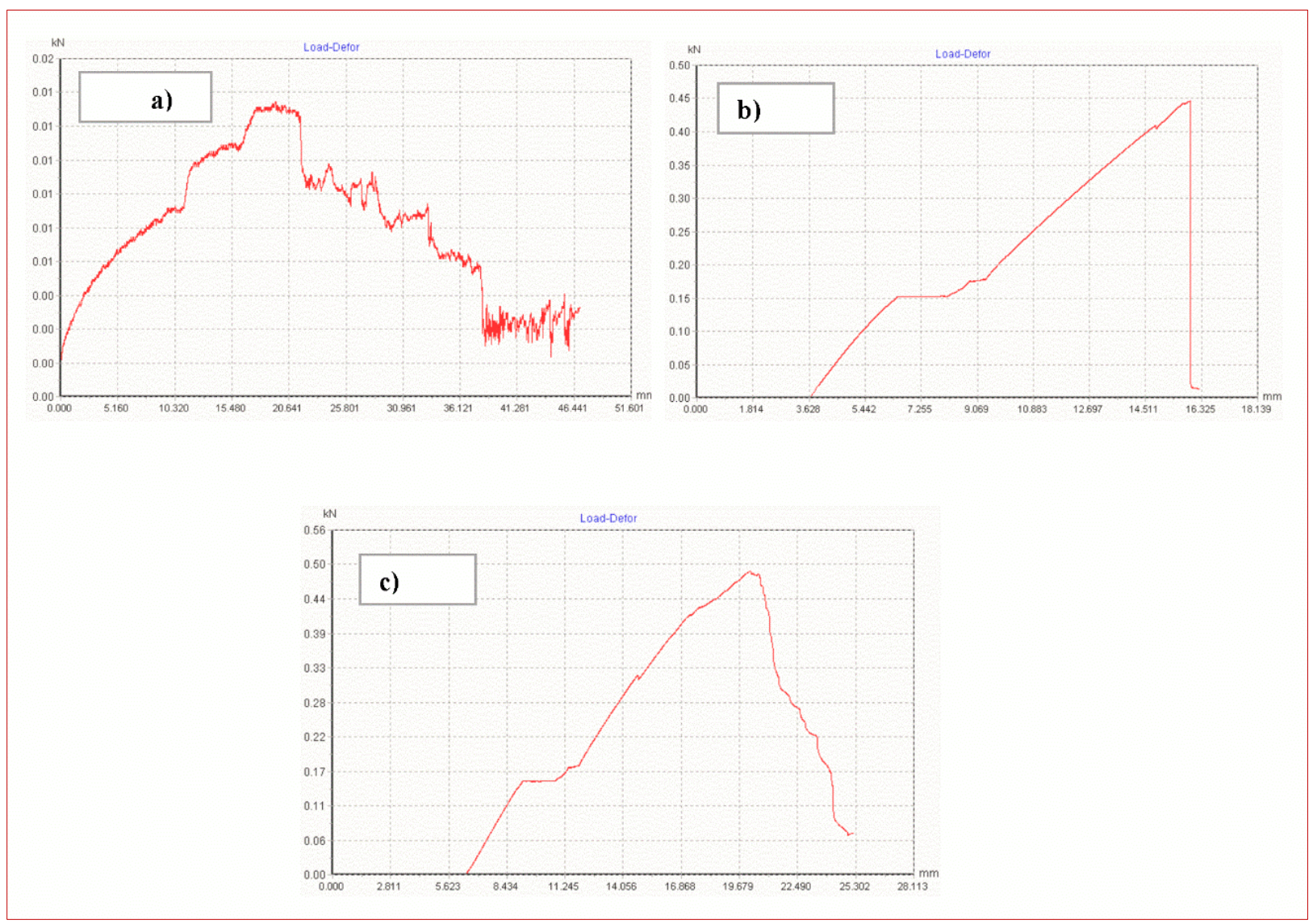

Figure 4 Load versus extension curve a) G/Epoxy b) J/Epoxy and c) hybrid composite J/G/Epoxy).

\section{Impact Testing}

In Izod impact test is performed to evaluate the impact strength of the manufactured composite specimens (ASTM D7136). 


\section{MORPHOLOGICAL ANALYSIS}

Scanning electron microscopy (SEM)(S-3700N Ultra Large VP-SEM) is adopted to study the interfacial damage of the developed composite specimens.

\section{RESULT AND DISCUSSION}

\section{Hardness}

Hardness behaviour of J/G/Epoxy composites and its hybrids is depicted in figure 5. Hybrid composites exhibit the highest Shore-D hardness value of 99. Accordingly, in each case of hardness value was observed to be highest as compared to neat epoxy resin. G/Epoxy composite has a Shore-d hardness value of 98 whereas J/Epoxy takes a Hardness value of 96 (Shore-D). The addition of different layers of natural fibre mat contributes to an improvement in the hardness value of the manufactured composites, according to the results.

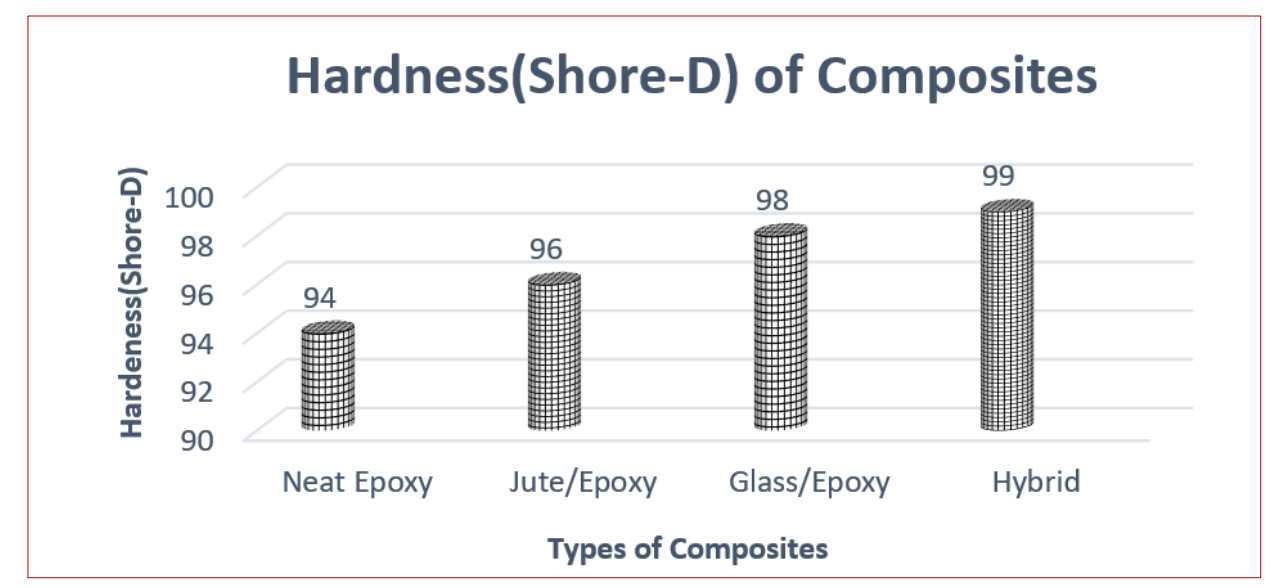

Figure 5 Hardness value: Neat epoxy, J/Epoxy, G/Epoxy and J/G/Epoxy(hybrid).

\section{Tensile Testing}

Tensile strength, young's modulus, and elongation at break (EOB) of the J/G/Epoxy composites are presented in Figures 06-08. As presented in Figure 6, the tensile strength of the fabricated composite laminates was found to be higher than that of pure epoxy specimens in each case. In the analyses, the mean strength of J/G/Epoxy laminates showed 165.38 MPa during tensile testing. The mean tensile strength of G/Epoxy was $150.92 \mathrm{MPa}$, while the minimum value of mean tensile strength for J/Epoxy was 96.33 MPa. In comparison to the neat epoxy, the developed composites and their hybrids exhibited a higher young's modulus with 
the addition of different natural fibre mats, as illustrated in Figure 7. The modulus of elasticity (Young's modulus) of the hybrid composite (J/G/Epoxy) was 1.93GPa. Jute/epoxy and glass/epoxy have Young's modulus of $1.78 \mathrm{GPa}$ and $1.43 \mathrm{GPa}$, respectively. The value of young's modulus is higher in each situation as compared to neat epoxy Resin. The Young's modulus of a natural fibre mat varies depending on the type of natural fibre mat used and how it interacts with the epoxy matrix.

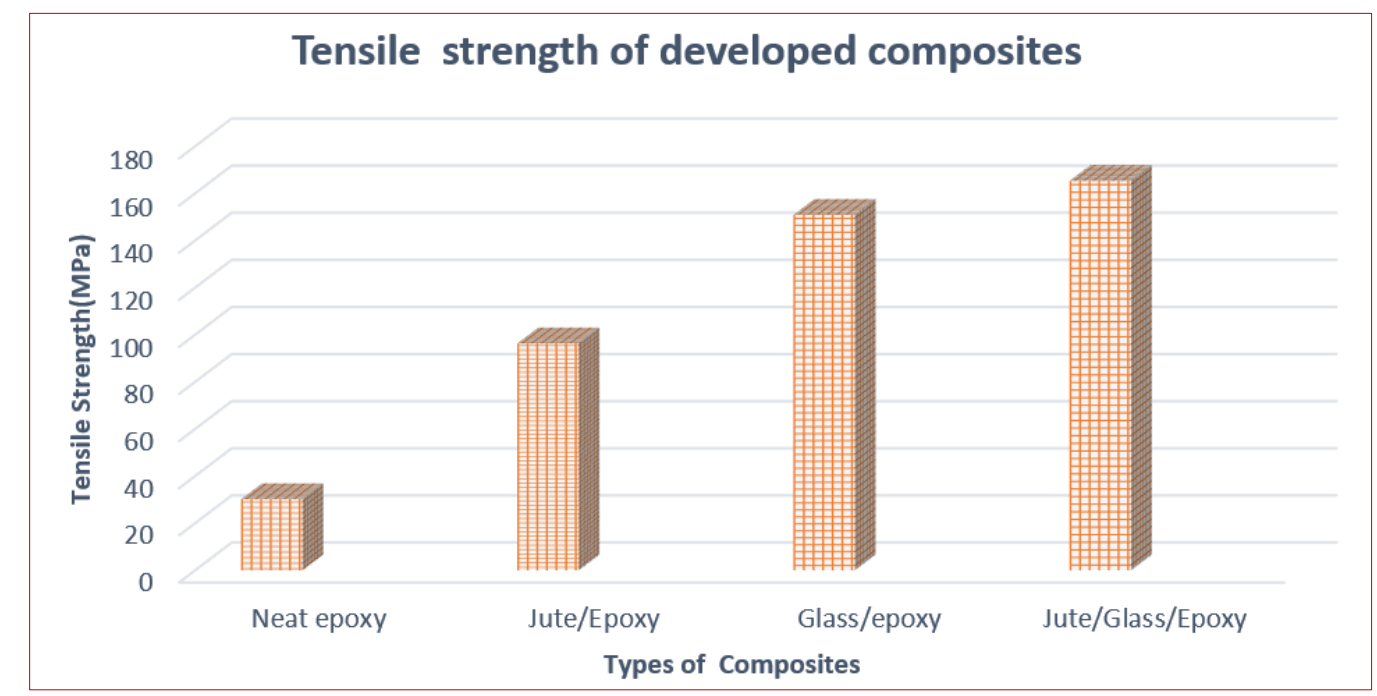

Figure 6 Tensile strength: Neat epoxy, J/Epoxy, G/Epoxy and J/G/Epoxy(Hybrid).

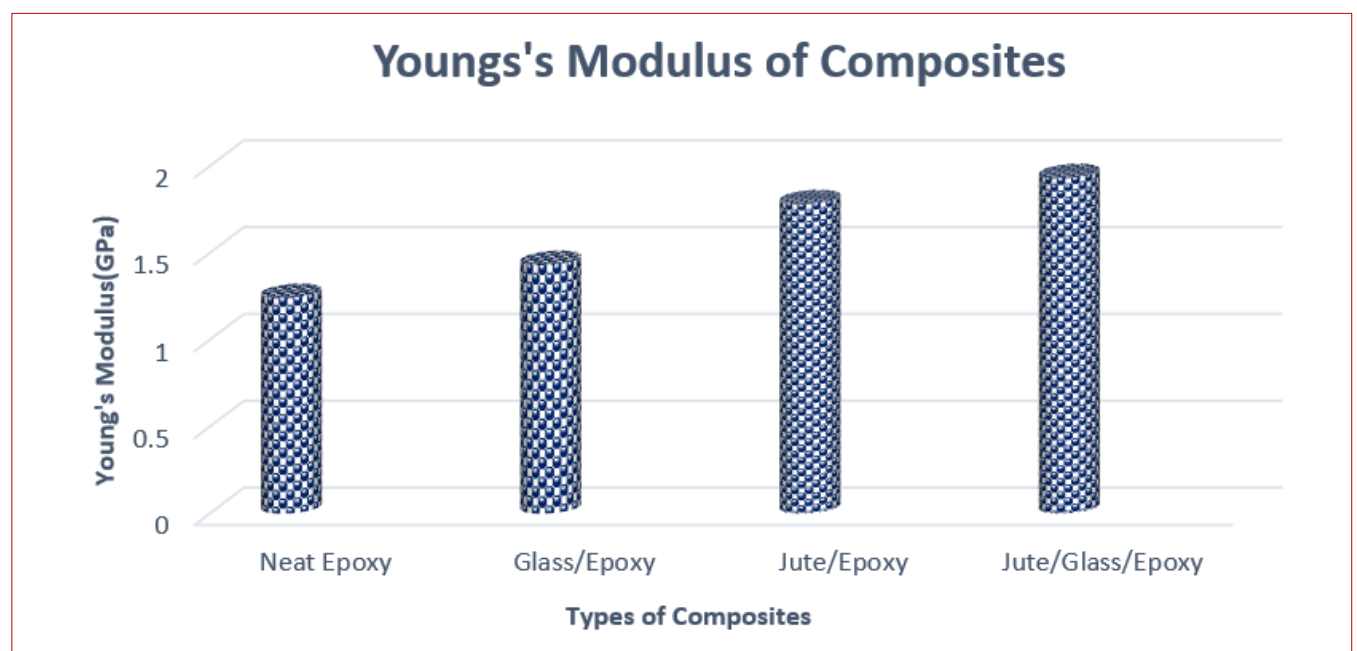

Figure 7 Young's Modulus: Neat epoxy, G/Epoxy, J/Epoxy, J/G/Epoxy.

During tensile testing, the material's elongation before breaking is also an important factor that aids in predicting whether the material will be brittle or ductile. Figure 8 illustrates the 
percentage elongation of formed composites and hybrids. The J/G/Epoxy composite's percentage elongation at break was limited to $6.03 \%$. The percentage elongation values of G/Epoxy and J/Epoxy composites, on the other hand, are $3.4 \%$ and $3.86 \%$ at break, respectively. When compared to neat epoxy resin, there is a considerable improvement in percentage elongation at break (3.2\%). This means that the manufactured composites were slightly more ductile than neat epoxy Resin when compared to neat epoxy Resin.

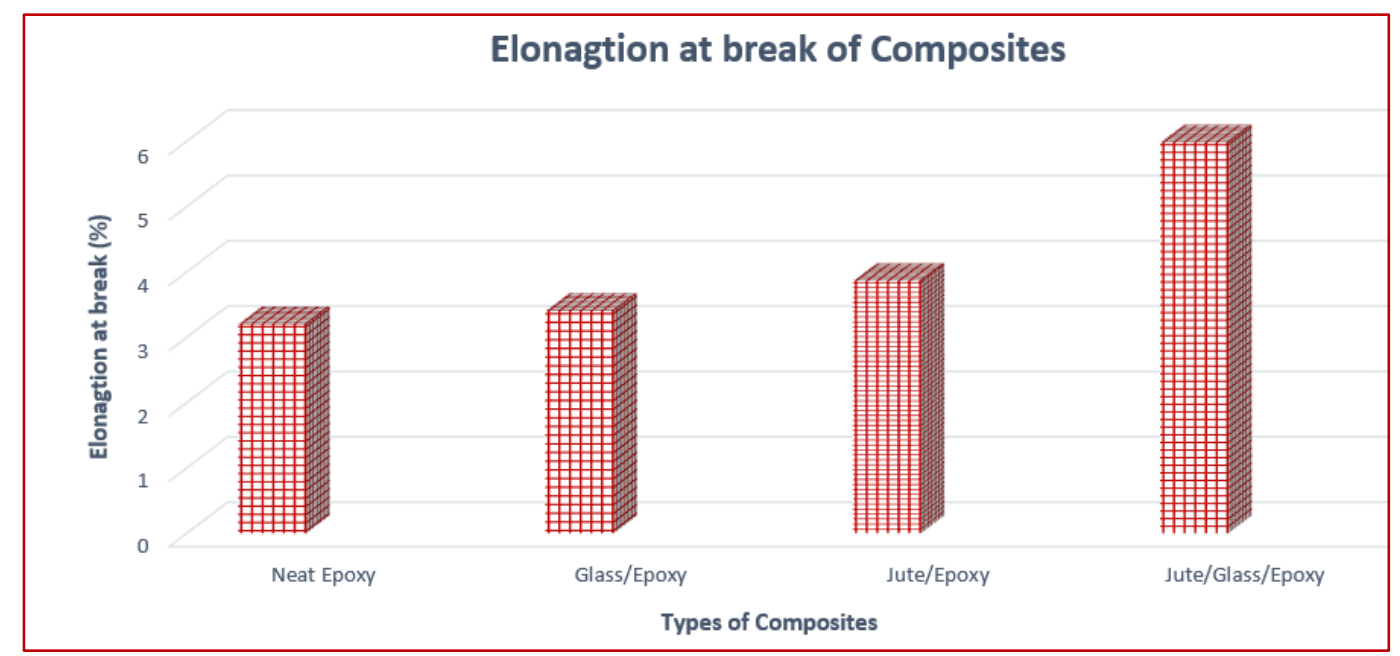

Figure $8 \%$ Elongation at break: Neat epoxy, G/Epoxy, J/Epoxy, J/G/Epoxy.

Following the tensile testing, SEM is used to evaluate the composites' interfacial damage. The micrographs obtained from SEM for the developed composites are shown in Figure 9. The degree of adhesion between the fibre and the matrix is observed to be influenced by the matrix's surface properties.
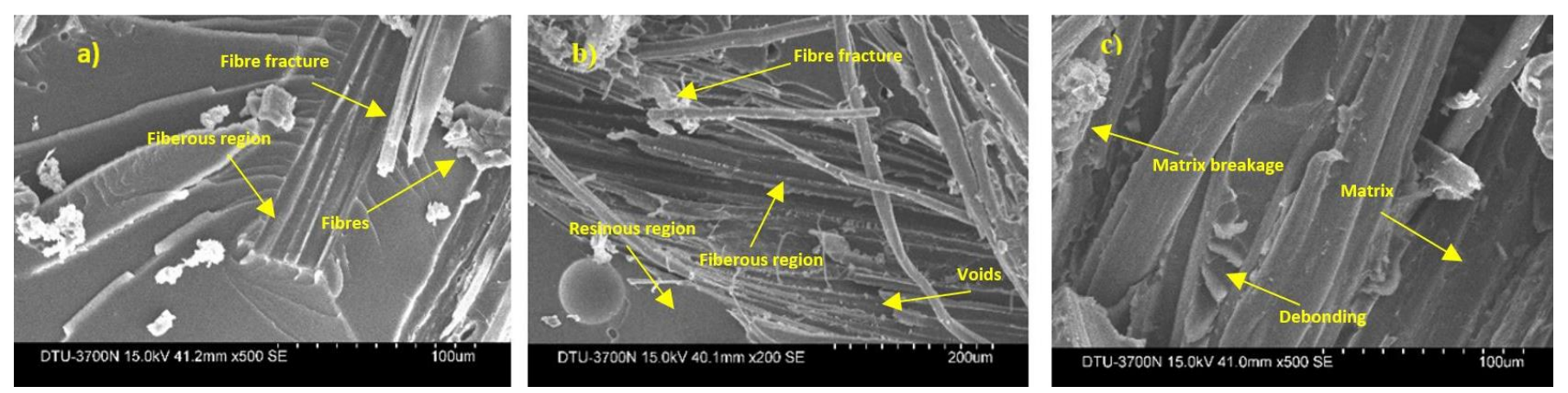

Figure 9 SEM images of the damaged specimens surfaces of tensile testing: a) G/Epoxy b) J/Epoxy and c) hybrid composites(J/G/Epoxy). 


\section{Flexural Testing}

Figures 10 and Figure 11 show the flexural strength and flexural modulus of the produced composites, respectively. The flexural strength of neat epoxy was found to be $34.96 \mathrm{MPa}$ and the modulus was found to be $0.64 \mathrm{GPa}$ during flexural testing. Hybrid composites made of jute and glass epoxy exhibited a maximum strength of $475.77 \mathrm{MPa}$ and a modulus of $1.958 \mathrm{GPa}$ when tested with neat epoxy in flexural testing. G/Epoxy also has a moderate strength of 152.6 $\mathrm{MPa}$ and an overall modulus of $1.62 \mathrm{GPa}$ during flexural testing. The J/Epoxy composite has a sufficient modulus of $1.46 \mathrm{GPa}$ and mentionable strength of $352.09 \mathrm{GPa}$ in flexural testing.

However, as compared to neat epoxy resin, the developed composites have a greater overall flexural strength and flexural modulus.

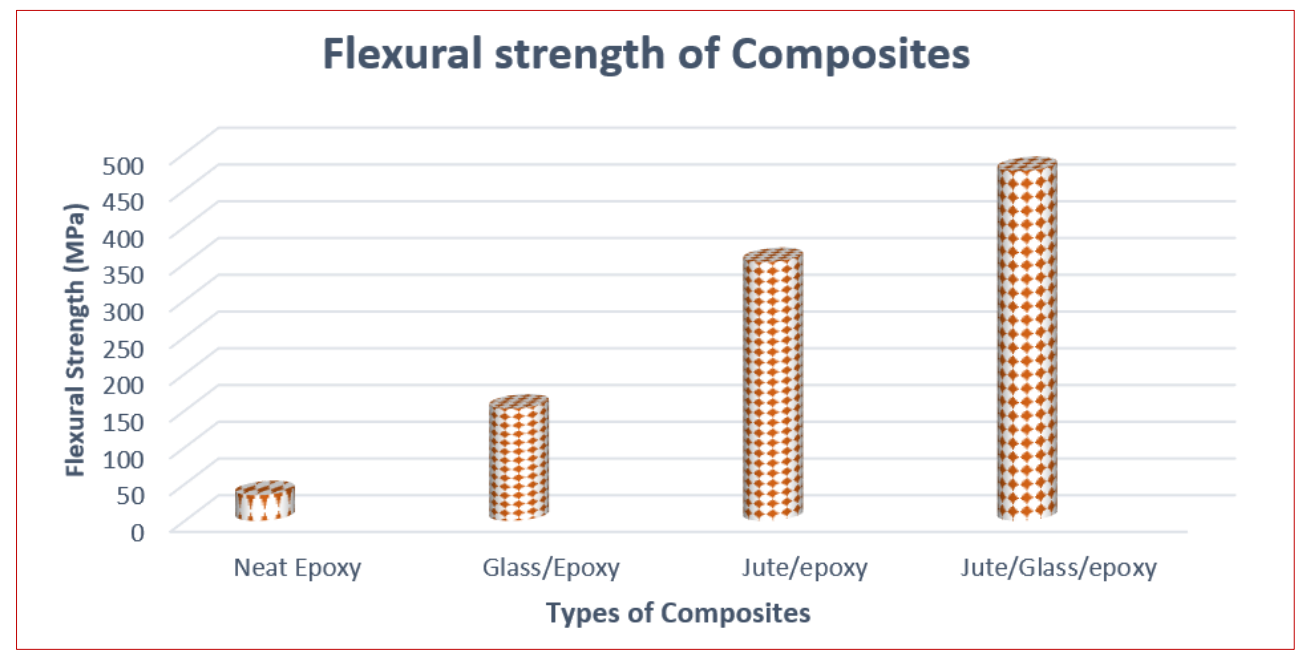

Figure 10 Flexural strength: Neat epoxy, G/Epoxy, J/Epoxy, J/G/Epoxy(Hybrid).

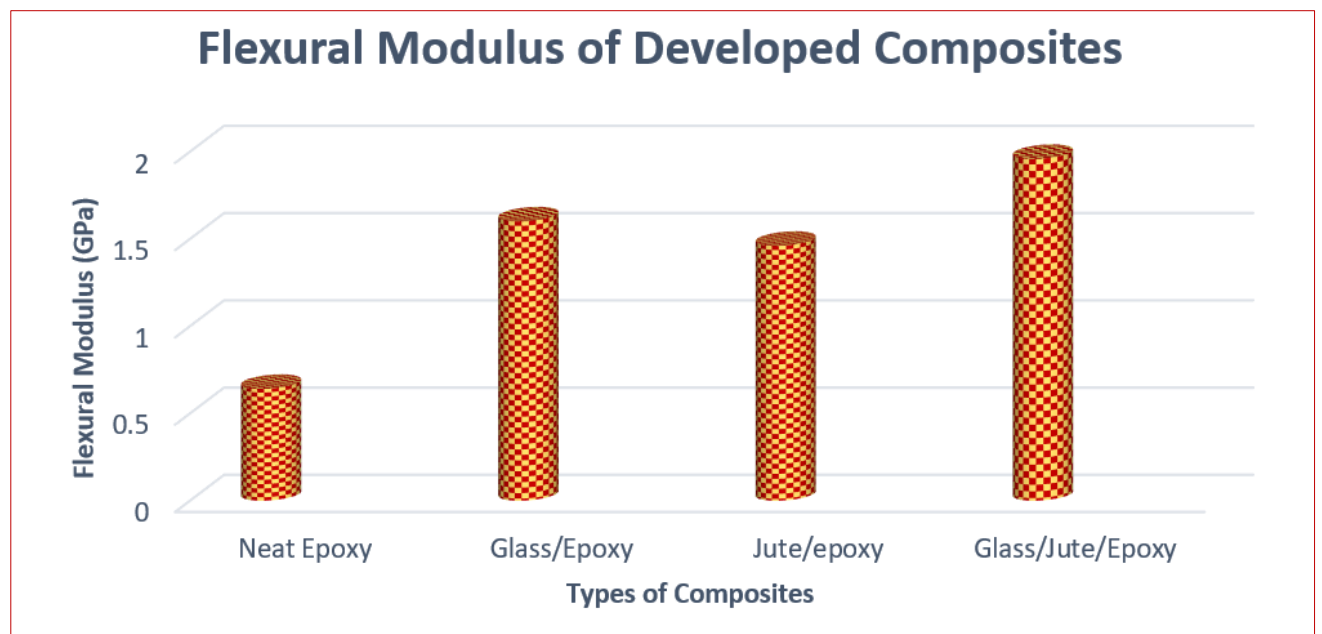


Figure 11 Flexural modulus: Neat epoxy, G/Epoxy, J/Epoxy, J/G/Epoxy(Hybrid).

After completion of flexural testing, damaged composites are evaluated using scanning electron microscopy to study the interfacial damage. Figure 12 shows the micrographs obtained from SEM for the developed composites. On the flexed and ruptured composites, the appearance of sharp edges, matrix cracking, delamination of layers and debonding of reinforcement and matrix can be easily visualised. In this study, J/G/Epoxy composites had lesser debonding between fibre and the matrix than that of the remaining developed composites.

The interfacial adhesion between the fibre and matrix is a crucial parameter that has a significant impact on the flexural strength of the composites developed.
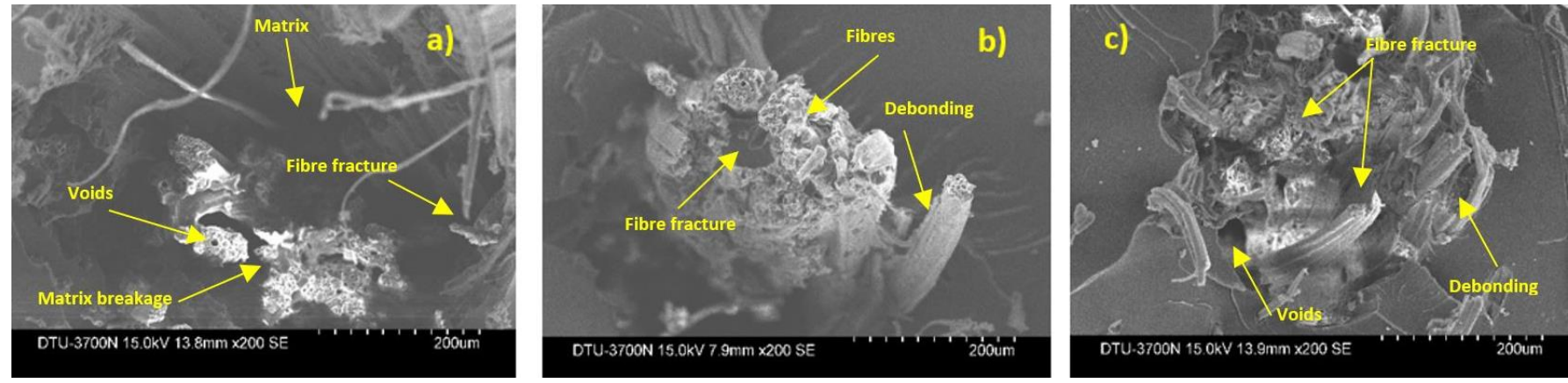

Figure 12 SEM images of the damaged fractured specimens of flexural testing: a) G/Epoxy b) J/Epoxy and c) hybrid composites(J/G/Epoxy).

\section{Impact Strength}

The impact strength of the manufactured composites is shown in Figure 13. The value of fabricated composites were found to be higher than those of neat epoxy having the impact strength of $4.6 \mathrm{~kJ} / \mathrm{m}^{2}$. In this test, the $\mathrm{J} / \mathrm{G} /$ Epoxy composite achieved highest impact strength value of $19.6 \mathrm{~kJ} / \mathrm{m}^{2}$. J/Epoxy composites showed a lower impact strength of $9.5 \mathrm{~kJ} / \mathrm{m}^{2}$, compared to $18.2 \mathrm{~kJ} / \mathrm{m}^{2}$ for $\mathrm{G} /$ Epoxy composites. 


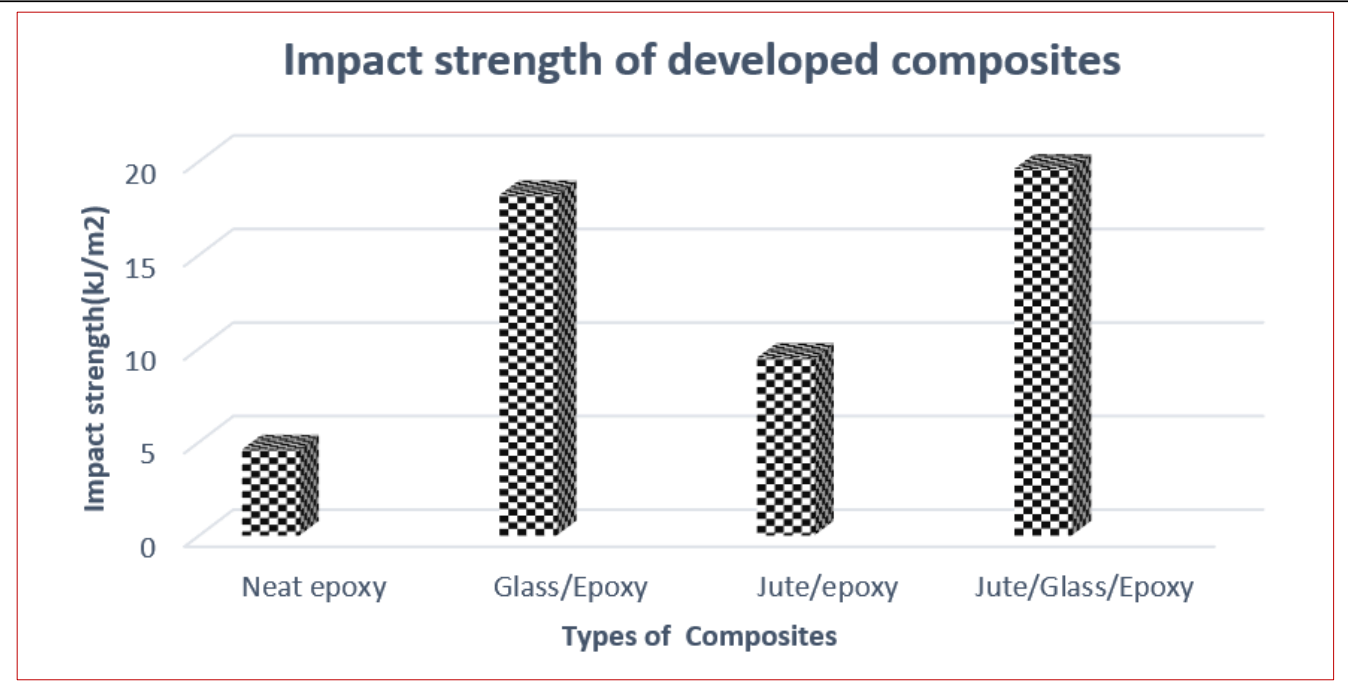

Figure 13 Impact strength of neat epoxy, G/Epoxy, J/Epoxy, J/G/Epoxy(hybrid).

After completion of impact testing, damaged composites are evaluated using scanning electron microscopy to study the interfacial damage. The micrographs obtained from SEM for the developed composites is shown in Figure 14.

J/G/Epoxy composites had lesser debonding between fibre and the matrix than that of the remaining developed composites and hence it has a higher value of impact strength.
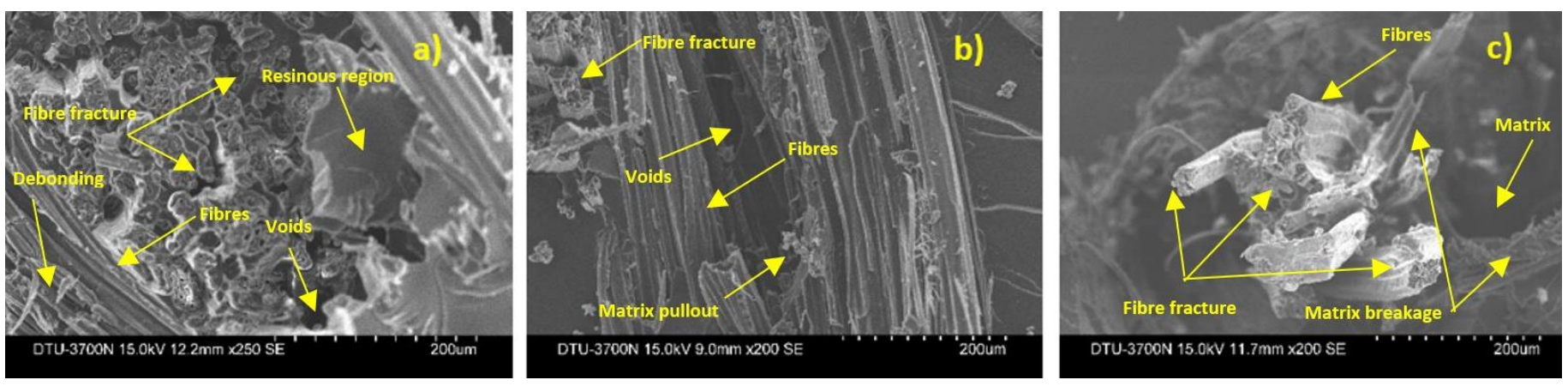

Figure 14 SEM images of the damaged specimens of impact testing: a) G/Epoxy b) J/Epoxy and c) hybrid composites (J/G/Epoxy).

\section{CONCLUSIONS}

Present research work emphasis on the development of $\mathrm{J} / \mathrm{G}$ fibre reinforced with epoxy resin using hand layup method. The following Conclusions of the present work are:

1. As compared to neat epoxy resin, the developed polymer composites had a much higher tensile strength. This demonstrates that using natural fibres improves tensile strength. The J/G/Epoxy(hybrids) composite has the highest value in terms modulus of elasticity 
(young's modulus), tensile strength, and \% elongation. It implies that the epoxy resin and the fibre are properly bonded.

2. J/Epoxy shows a minimum value of tensile strength, whereas glass/epoxy takes a minimum value for young's modulus and \% elongation.

3. As the constituent materials (fibre mat + epoxy matrix) act as a single unit against a flexural load, an increase in the value of flexural strength of the developed composites is observed. However, developed hybrid composites ( $\mathrm{J} / \mathrm{G} /$ Epoxy) take a maximum value of flexural strength and flexural modulus of $475.77 \mathrm{MPa}$ and $1.95 \mathrm{GPa}$, respectively.

4. J/Epoxy showed a minimum value of impact strength of $9.5 \mathrm{~kJ} / \mathrm{m}^{2}$ with respect to the other developed composites. Furthermore, hybrid composite (J/G/Epoxy) again achieved a maximum value of impact strength. This shows that they have a proper energy absorbing capacity.

5. During mechanical testing, SEM is adopted to investigate the interfacial damages in the fibre and matrix.

\section{REFERENCES}

Awal, A., Rana, M., \& Sain, M. (2015). Thermorheological and mechanical properties of cellulose reinforced PLA bio-composites. Mechanics of Materials. https://doi.org/10.1016/j.mechmat.2014.09.009

Bajpai, P. K., Ahmad, F., \& Chaudhary, V. (2019). Processing and characterization of biocomposites. In Handbook of Ecomaterials. https://doi.org/10.1007/978-3-319-68255-6_98

Chaudhary, V., \& Ahmad, F. (2020). A review on plant fiber reinforced thermoset polymers for structural and frictional composites. In Polymer Testing. https://doi.org/10.1016/j.polymertesting.2020.106792

Chaudhary, V., Bajpai, P. K., \& Maheshwari, S. (2018). Studies on Mechanical and Morphological Characterization of Developed Jute/Hemp/Flax Reinforced Hybrid Composites for Structural Applications. Journal of Natural Fibers. https://doi.org/10.1080/15440478.2017.1320260

Chaudhary, V., Sahu, R., Manral, A., \& Ahmad, F. (2019). Comparative study of mechanical properties of dry and water aged jute/flax/epoxy hybrid composite. Materials Today: Proceedings. https://doi.org/10.1016/j.matpr.2019.11.053

Das, P. P., Chaudhary, V., \& Mishra, S. (2021). Emerging Trends in Green Polymer Based Composite Materials: Properties, Fabrication and Applications. In Graphene Based Biopolymer Nanocomposites (pp. 1-24). Springer. 
Das, P. P., Chaudhary, V., \& Motha, S. J. (2020). Fabrication and Characterization of Natural Fibre Reinforced Polymer Composites: A Review. SSRN Electronic Journal, 119-123. https://doi.org/10.2139/ssrn.3569437

Das, P. P., Srinivasa Rao, G., Mussada, E. K., Babu Rao, G., Sharma, B. P., \& Vates, U. K. (2020). Fabrication and Tensile Testing of DHAK Fiber Reinforced Polyester Composites. Advances in Production and Industrial Engineering, 53-61. https://doi.org/10.1007/978-981-15-5519-0_5

Faruk, O., Bledzki, A. K., Fink, H. P., \& Sain, M. (2012). Biocomposites reinforced with natural fibers: 2000-2010. In Progress in Polymer Science. https://doi.org/10.1016/j.progpolymsci.2012.04.003

Ku, H., Wang, H., Pattarachaiyakoop, N., \& Trada, M. (2011). A review on the tensile properties of natural fiber reinforced polymer composites. Composites Part B: Engineering. https://doi.org/10.1016/j.compositesb.2011.01.010

Manickam, C., Kumar, J., Athijayamani, A., \& Diwahar, N. (2015). Mechanical and wear behaviors of untreated and alkali treated Roselle fiber-reinforced vinyl ester composite. Journal of Engineering Research. https://doi.org/10.7603/s40632-015-0025-4

Nabi Saheb, D., \& Jog, J. P. (1999). Natural fiber polymer composites: A review. Advances in Polymer Technology. https://doi.org/10.1002/(SICI)1098-2329(199924)18:4<351::AIDADV6>3.0.CO;2-X

Porras, A., Maranon, A., \& Ashcroft, I. A. (2016). Thermo-mechanical characterization of Manicaria Saccifera natural fabric reinforced poly-lactic acid composite lamina. Composites Part A: Applied Science and Manufacturing. https://doi.org/10.1016/j.compositesa.2015.11.008

Pratim Das, P., \& Chaudhary, V. (2020). Tribological and dynamic mechanical analysis of biocomposites: A review. Materials Today: Proceedings, 25(xxxx), $729-734$. https://doi.org/10.1016/j.matpr.2019.08.233 